\title{
First record of Pelecinus polyturator (Drury, 1773) (Hymenoptera: Pelecinidae) from Ceará state, Brazil
}

\author{
Antonio W. A. Soares ${ }^{1(\infty)}$, Diego G. Pádua ${ }^{2=-\infty}$, Jober F. Sobczak ${ }^{1,3(0)}$
}

${ }^{1}$ Universidade da Integração Internacional da Lusofonia Afro-Brasileira - UNILAB, Redenção, CE, Brazil. ${ }^{2}$ Instituto Nacional de Pesquisas da Amazônia, INPA - Manaus, AM, Brazil. ${ }^{3}$ Universidade Federal do Ceará - UFC, Fortaleza, CE, Brazil.

㭋Corresponding author: paduadg@gmail.com

\author{
Edited by: Daniel Aquino
}

Received: November 08, 2021. Accepted: December 27, 2021. Published: February 15, 2022.

\begin{abstract}
We record for the first time the species Pelecinus polyturator (Drury, 1773) in the Ceará state, Brazil. Most specimens were collected in March, the peak of the rainy season in the humid mountain ranges. In addition, digital images of the $P$. polyturator and a map with the geographical distribution of the species are presented.
\end{abstract}

Keywords: Hotspot, Maciço de Baturité, Parasitoid wasp, Proctotrupoidea, Scarabaeidae.

Pelecinus polyturator (Drury, 1773) (Hymenoptera: Pelecinidae) is a parasitoid wasp with coloration metallic black in general. Females have a specialized metasoma and a medium to large body, measuring between 20 and $90 \mathrm{~mm}$ in length, while males have simple metasoma and usually do not exceed $15 \mathrm{~mm}$ (Shih et al. 2010). They occur in practically the entire American continent, from Canada to Argentina, females are usually more easily found, and males are much rarer (Masner 1993).

As far as the habit of these animals is concerned, they are koinobiont endoparasites. They are usually found parasitizing beetle larvae of the Phyllophaga Harris, 1827 genus (Scarabaeidae), using their huge and flexible specialized metasoma to penetrate the soil and encounter the larvae (Lim \& Stewart 1980; Mason 1984). More details of this host-seeking behavior were obtained by Bennett (2003), who demonstrated that females can reach larvae that are around $5 \mathrm{~cm}$ below the soil surface, inserting the entire metasoma into the soil and even a portion of the mesosoma.

In Brazil, studies on this group of parasitoid wasps are more concentrated in the Southeast region of the country (Lara \& Perioto 2014), and recent studies demonstrate the occurrence of this species in several Brazilian states with a gap in knowledge in the Northeast region (Lara 2015; Sousa et al. 2020). The wasp fauna in the state of Ceará is poorly known, with only 97 species recorded (Sobczak et al. 2021).

The work was carried out in the region known as the Morro do Chapéu, localized inside the Vale das Nuvens Hotel $\left(4^{\circ} 15^{\prime} 5.9^{\prime \prime} \mathrm{S}\right.$, $38^{\circ} 55^{\prime} 1.4^{\prime \prime} \mathrm{W}$ ), Guaramiranga municipality, Ceará state, Brazil (Fig. 1 ). The region is characterized by the remnant vegetation of humid forest and one of the high swamps found in the state of Ceará (Souza \& Oliveira 2006). It is a mountain region with an altitude of $945 \mathrm{~m}$ at the study site. As a remnant of rainforest located within the Caatinga biome, its age dating back to the Cretaceous period, the region is considered a biodiversity hotspot and probably harbor a great diversity of species and a rate of endemism (Bétard et al. 2007).

The collects were carried out from October 2018 to October 2019. Five traps of flight intercept (Malaise trap) were installed within the forest, 300 meters away from each other, two of which were installed at the base of the hill and three at the top. The collections were carried out with an interval of 30 days. The vouchers were deposited in the
Invertebrate Collection at Instituto Nacional de Pesquisas da Amazônia (INPA) (51 females and two males) and Ecology and Evolution Laboratory at Universidade da Integração Internacional da Lusofonia Afro-Brasileira (UNILAB) (four females and four males).

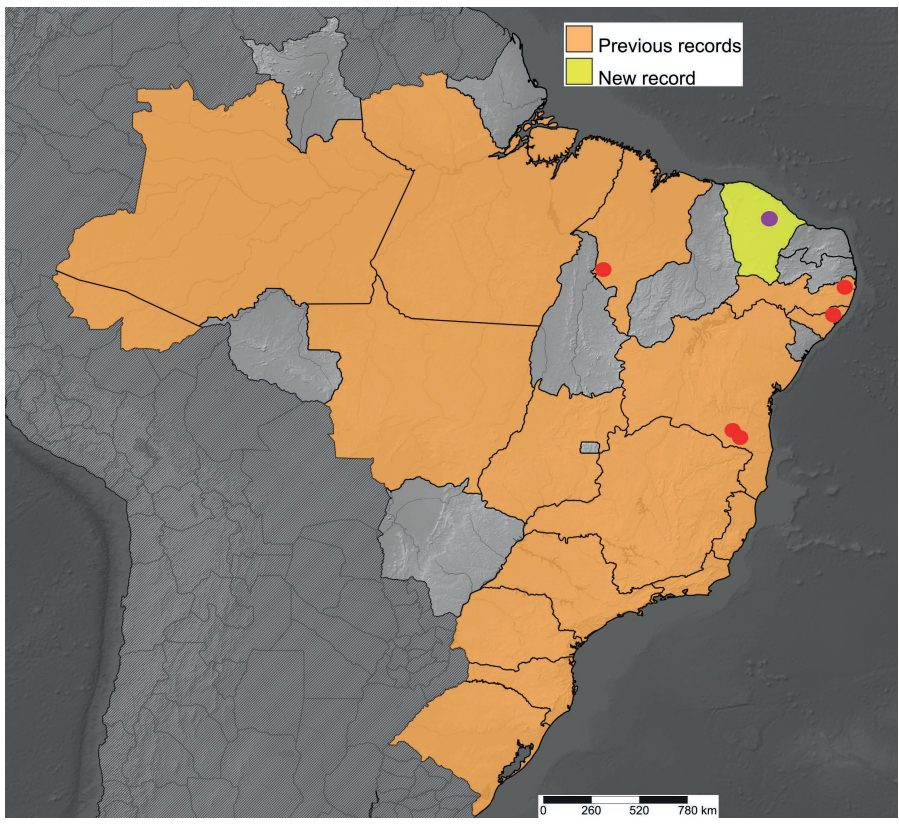

Figure 1. Geographic distribution of Pelecinus polyturator (Drury, 1773) (Hymenoptera: Pelecinidae) in Brazil. Red circles = previous records in Northeast Brazil; Purple circle $=$ new record.

Digital images were taken at Invertebrate Collection (INPA) using a Leica DMC4500 digital camera attached to a Leica M205A stereomicroscope and combined using the software Helicon Focus 5.3 Pro. The map was made through the website SimpleMappr (Shorthouse 2010).

A total of 61 specimens were collected, being mostly females $(n=$ 55 ) and only six males (Figs. 2A, 2B). March was the month with the highest numbers of specimens collected (Tab. 1), which is possibly directly connected with the peak of the rainy season. In the work of Lara \& Perioto (2014), P. polyturator specimens were also collected in 


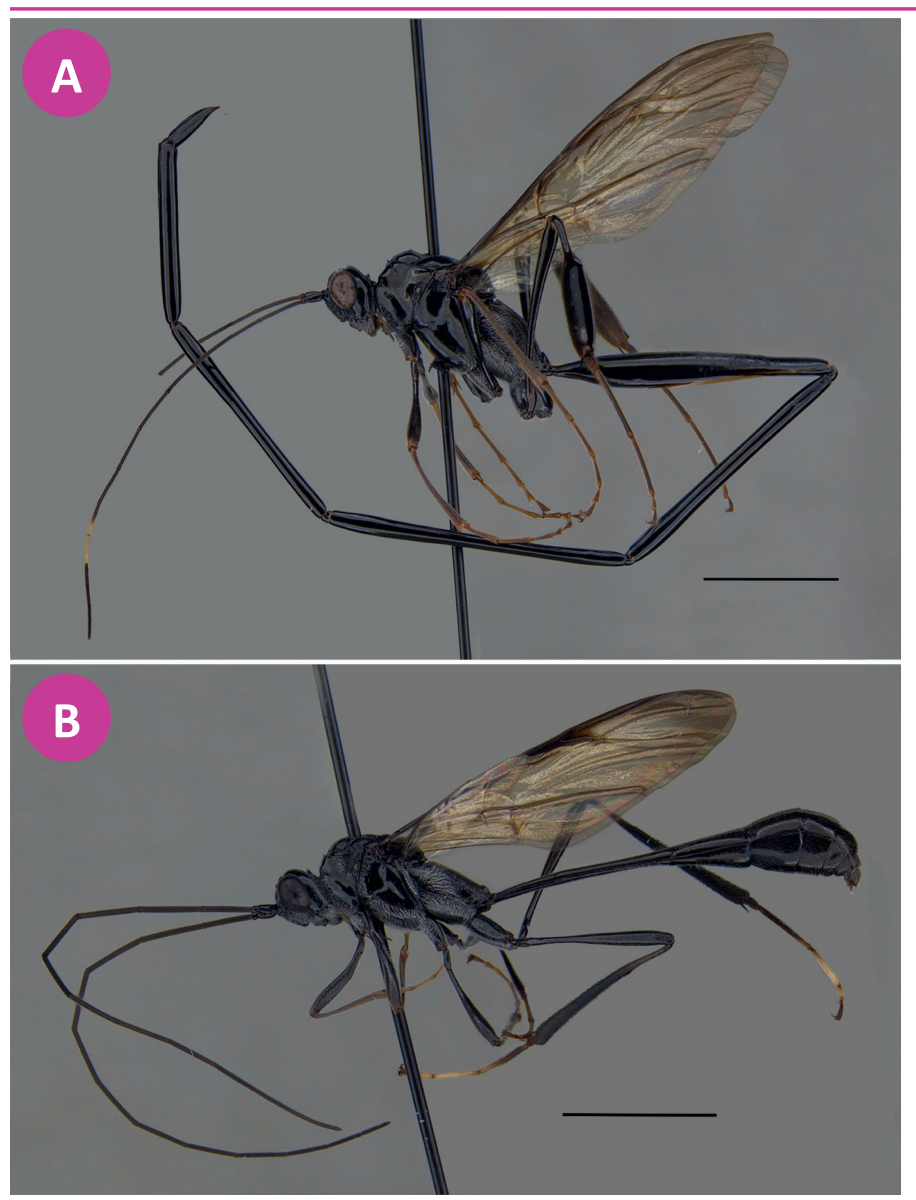

Figure 2. Pelecinus polyturator (Drury, 1773) (Hymenoptera: Pelecinidae) collected in the Morro do Chapéu, Ceará, Brazil. A. Habitus, female; B. Habitus, male. Scale bars: $5 \mathrm{~mm}$.

Table 1. Individuals of Pelecinus polyturator (Drury) (Hymenoptera: Pelecinidae) collected with Malaise trap, during the one year, in rainforest fragment of the Morro do Chapéu in the state of Ceará, Brazil.

\begin{tabular}{cccc}
\hline Month/year & Females & Males & Total \\
\hline Nov. 2018 & 0 & 0 & 0 \\
\hline Dec. 2018 & 0 & 0 & 0 \\
\hline Jan. 2019 & 11 & 2 & 13 \\
\hline Feb. 2019 & 12 & 2 & 14 \\
\hline Mar. 2019 & 31 & 1 & 32 \\
\hline Apr. 2019 2019 & 1 & 0 & 1 \\
\hline May. 2019 2019 & 0 & 0 & 0 \\
\hline Jun. 2019 2019 & 0 & 1 & 1 \\
\hline Jul. 2019. 2019 & 0 & 0 & 0 \\
\hline Aug. 2019 & 0 & 0 & 0 \\
\hline Sep. & 0 & 0 & 0 \\
\hline Oct. 2019 & 0 & 0 & 0 \\
\hline
\end{tabular}

the rainy season in the Atlantic Rainforest of São Paulo State, Brazil.

Pelecinus polyturator is registered in Brazil for the states of Amazonas, Pará, Acre, Mato Grosso, Goiás, Maranhão, Bahia, Alagoas, Pernambuco, Minas Gerais, Espírito Santo, Rio de Janeiro, São Paulo, Paraná, Santa Catarina, Rio Grande do Sul (Fig. 1) (Lara 2015; Souza et al. 2020). The new record of $P$. polyturator to Ceará state it is an addition to the state's fauna, and also shows the importance of high-altitude swamps that can harbor important biodiversity to be discovered.

\section{Acknowledgments}

We thank Instituto Nacional de Ciência e Tecnologia dos Hymenoptera Parasitoides (HYMPAR) for providing us with Malaise traps used in this study. The Vale das Nuvens Hotel authorized us to do the work on its property. The Invertebrate Collection of INPA for the possibility to use the layer-photo equipment. To FUNCAP - PS10186-00411.01.00/21 (research grants to J.F. Sobczak). This study was financed in part by the Coordenação de Aperfeiçoamento de Pessoal de Nível Superior - Brasil (CAPES), Finance Code 001 (D.G. Pádua PNPD/CAPES proccess $\left.n^{\circ} 88887.372005 / 2019-00\right)$.

\section{Authors' Contributions}

A.W.A.S. and J.F.S. collected the specimens; D.G.P. identified the material and produced the digital images and map. All authors wrote the manuscript, discussed the results, and contributed to its final version.

\section{Conflict of Interest Statement}

The authors declare no conflict of interest.

\section{References}

Bennett, A. M. R. (2003) Host location behavior in Pelecinus polyturator (Hymenoptera: Pelecinidae). Journal of the Entomological Society of Ontario, 34: 131-134.

Bétard, F.; Peulvast, J. P.; Sales, V. C. (2007) Caracterização Morfopedologica de uma serra úmida no semiárido do Nordeste brasileiro: o caso do maciço de Baturité-CE. Mercator, 6(12): 107126.

Lara, R. I. R. (2015) Pelecinidae in Catálogo Taxonômico da Fauna do Brasil. PNUD. http://fauna.jbrj.gov.br/faunadobrasil/90435. Access on: viii.2021.

Lara, R. I. R.; Perioto, N. W. (2014) Seasonality of Pelecinus polyturator (Drury) (Hymenoptera, Pelecinidae) in the Atlantic Rainforest of São Paulo State, Brazil. Revista Brasileira de Entomologia, 58(1): 63-65. doi: 10.1590/S0085-56262014000100010

Lim, K. P.; Stewart, R. K. (1980) A note on Pelecinus polyturator (Hymenoptera: Pelecinidae), a parasite of Phyllophaga anxia (Coleoptera: Scarabaeidae). The Canadian Entomologist, 112(2): 219-220. doi: 10.4039/ent112219-2

Masner, L. (1993) Superfamily Proctotrupoidea. In: Goulet, H.; Huber, J. (Eds.) Hymenoptera of the world: an identification guide to families, pp. 537-557. Ottawa: Agriculture Canada.

Mason, W. R. M. (1984) Structure and movement of the abdomen of female Pelecinus polyturator (Hymenoptera: Pelecinidae). The Canadian Entomologist, 16(3): 419-426. doi: 10.4039/ent116419-3

Shih, C.; Feng, H.; Liu, C.; Zhao, Y. (2010) Morphology, phylogeny, evolution, and dispersal of Pelecinidae wasps (Hymenoptera: Pelecinidae) over 165 million years. Entomological Society of America, 103(6): 875-885. doi: 10.1603/an09043

Shorthouse, D. P. (2010) SimpleMappr, an online tool to produce publication-quality point maps. http://www.simplemappr.net/. Access on: viii.2021.

Sobczak, J. F.; Pádua, D. G.; Schoeninger, K.; Somavilla, A.; Bartolomay, P. R. (2021) Lista de Vespas do Ceará. Fortaleza: Secretaria do Meio Ambiente do Ceará. https://www.sema.ce.gov.br/fauna-do-ceara/ invertebrados/vespas. Access on: viii.2021.

Sousa, A. F. A.; Nascimento, A. C.; Tavares, M. T.; Fernandes, D. R. R. (2020) New records of Pelecinus polyturator (Drury) (Hymenoptera: Proctotrupoidea: Pelecinidae) for Brazil. Revista Chilena de Entomología, 46(4): 739-743. doi: 10.35249/rche.46.4.20.20

Souza, M. J. N.; Oliveira, V. D. P. (2006) Os enclaves úmidos e sub-úmidos do semiárido do Nordeste brasileiro. Mercator, 5(9): 85-102. 